scanning. Chest, 118(3), 615-624.

4. Schenk P., Schöniger-Hekele M., Fuhrmann V. và cộng sư. (2003). Prognostic significance of the hepatopulmonary syndrome in patients with cirrhosis. Gastroenterology, 125(4), 1042-1052.

5. Rodriguez-Roisin R. và Roca J. (1997). Hepatopulmonary syndrome: the paradigm of liverinduced hypoxaemia. Baillieres Clin Gastroenterol, 11(2), 387-406.

6. Rodríguez-Roisin R. và Krowka M.J. (2008), Hepatopulmonary syndrome--a liver-induced lung vascular disorder. N Engl J Med, 358(22), 2378-2387.

7. Lasch H.M., Fried M.W., Zacks S.L. và cộng sự.
(2001). Use of transjugular intrahepatic portosystemic shunt as a bridge to liver transplantation in a patient with severe hepatopulmonary syndrome. Liver Transpl, 7(2), 147-149.

8. Swanson K.L., Wiesner R.H., và Krowka M.J. (2005). Natural history of hepatopulmonary syndrome: Impact of liver transplantation. Hepatology, 41(5), 1122-1129.

9. Pascasio J.M., Grilo I., López-Pardo F.J. và cônng sư. (2014). Prevalence and severity of hepatopulmonary syndrome and its influence on survival in cirrhotic patients evaluated for liver transplantation. Am J Transplant, 14(6), 1391-1399.

\title{
PHƯƠNG PHÁP SẢN XUẤT MẪU NƯỚC TIỂU GIẢ ĐỊNH ỨNG DỤNG TRONG CHƯO'NG TRÌNH NGOẠI KIỂM TỔNG PHÂN TÍCH NƯớC TIỂU
}

\section{TÓM TẮT}

Mục tiêu: Đánh giá chất lượng mẫu nước tiểu giả định sử dụng trong chương trình ngoại kiểm tống phân tích nước tiểu. Đánh giá tính đồng nhất và độ ổn đinh của bố mẫu đã sản xuất thử nghiêm theo tiêu chuẩn ISO GUIDE 35:2017. Phương pháp: Mẫu nước tiểu bình thường được sản xuất và làm nền để sản xuất bộ mẫu nước tiểu bất thường với những thông số (tỷ trọng (Specific Gravity - SG), pH, glucose (GLU), protein (PRO), urobilinogen (URO), bilirubin (BIL), nitrite (NIT), leukocyte (LEU), keton (KET), blood (BLO)) đã định trước. Đeánh giá tiên phân tích và đánh giá độ đồng nhất bộ mẫu trước khi chia thành 2 lô bảo quản ở 2 điều kiên nhiêt độ khác nhau là $2-8^{\circ} \mathrm{C}$ và $20^{\circ} \mathrm{C}$. Sau đó đánh giá độ ổn định dài hạn trong 3 tháng tại 6 thời điểm là 1 tuần, 2 tuần, 4 tuần, 6 tuần, 8 tuần và 12 tuần. Đánh giá độ ổn định ngắn hạn trong điều kiện vận chuyển sau 5 ngày, 8 ngày và 10 ngày gửi mẫu đển các phòng xét nghiệm tham gia. Kết quả: Sản xuất được mẫu nước tiểu giả đinh bất thường nhằm ứng dụng vào chương trình ngoại kiểm tổng phân tích nước tiểu10 thông số. Bộ mẫu sau khi sản xuất đạt độ đồng nhất (giá trị p các thông số đều lớn hơn 0.05). Mẫu nước tiểu sản xuất ra đạt độ ổn định trong thời hạn 3 tháng ởđiều kiện nhiệt độ $-20^{\circ} \mathrm{C}$ (p>0.05). Riêng bộ mấu giữ ở $2-8^{\circ} \mathrm{C}$, có LE் ổn định chỉ trong 6 tuần, URO ổn định trong 8 tuần, các thổng số SG, pH, GLU, PRO, NIT, KET, BLO ổn đinh trong 12 tuần $(p>0.05)$. Đối với độ ổn định ngẳn hạn, các thông số leukocytes, bilirubin và urobilinogen đạt độ ổn định trong thời gian 8 ngày vận chuyển, các thông

${ }^{1}$ Đai học y dượ Tp. Hồ Chí Minh

${ }^{2}$ Trung tâm Kiểm chuẩn chất lượng xét nghiệm Y học - Đai hoc Y Dước Tp. Hồ Chí Minh

Chịu trách nhiệm chính: Vũ Quang Huy

Email: drvuquanghuy@gmail.com

Ngày nhận bài: 19.10.2020

Ngày phản biên khoa hoc: 25.11.2020

Ngày duyệt bài: 9.12.2020
Vũ Quang Huy ${ }^{1,2}$, Lê Văn Chương ${ }^{1,2}$, Trần Nhật Nguyên ${ }^{2}$, Huỳnh Thị Diễm Phúc ${ }^{2}$

sỗ còn lại đạt độ ổn định trong thời gian 10 ngày vận chuyển ( $p$-value > 0.05). Kết luận: Xây dựng hoàn chî̉nh quy trình sản xuất mấu ngoại kiểm nước tiểu. Mẫu nước tiểu giả định đạt độ đồng nhất sau khi sản xuất. Đạt độ ổn định dài hạn trong vòng 3 tháng ở $20^{\circ} \mathrm{C}, 6$ tuần ở $2-8^{\circ} \mathrm{C}$, đạt độ ổn định ngắn hạn 8 ngày trong điều kiện vận chuyển mẫu sản xuất đủ điều kiện sử dụng cho chương trinh ngoại kiểm tổng phân tích nước tiểu.

Tư khóa: Tổng phân tích nước tiểu, ngoại kiểm, độ ổn định, độ đồng nhất.

\section{SUMMARY \\ PRODUCTION METHOD OF SIMULATED URINE UTILIZED IN URINALYSIS}

EXTERNAL QUALITY ASSESSMENT SCHEME

Objectives: To study methods of producing simulated urine samples used in external quality assessment (EQA) program. The homogeneity and stability of producing samples was evaluated according to ISO GUIDE 35:2017. Methods: Ten parameters (density (Specific Gravity-SG), pH, glucose (GLU), protein (PRO), urobilinogen (URO), bilirubin (BIL), nitrite (NIT), leukocyte (LEU), keton (KET), blood (BLO)) of normal urine sample were adjusted to produce abnormal urine sample with predetermined characteristics. The sets of producing samples were evaluated for pre-analysis and assessment of homogeneity then divided into 2 lots and stored at different temperature conditions $\left(2-8^{\circ} \mathrm{C}\right.$ and $\left.-20^{\circ} \mathrm{C}\right)$. The long-term stability is assessed for 3 months at 6 periods of time comprising: $1,2,4,6,8$ and 12 weeks. Sort-term stability was evaluated in the shipping conditions after 5, 8 and 10 days deliver to participant laboratories. Results: Two batches of simulated urine samples have been produced and evaluated for homogeneity and stability. All sample lots were homogenous ( $p$ value $>0.05$ ). All parameters of simulated urine were stable in 3 months at $-20^{\circ} \mathrm{C}$ ( $p>0.05$ ). However, at $2-8^{\circ} \mathrm{C}$ LEU and BIL were stable in 6 weeks, URO was stable in 8 weeks, the other 
parameters (SG, pH, GLU, PRO, NIT, KET and BLO) were stable in 12 weeks. For short-term stability, parameters LEU, BIL and URO were stable during 8 days, the other parameters were stable over 10 days of transporting condition ( $p$-value> 0.05). Conclusions: The procedure of simulated urine production has completely developed. The producing samples were reached the criteria for homogeneity and stability. Simulated urine was stable 3 months in storage $\left(-20^{\circ} \mathrm{C}\right)$ and 8 days in shipping condition. The producing samples are suitable to apply for urinalysis EQA program.

Keywords: external quality assessment, urinalysis, homogeneity, stability

\section{I. ĐẶT VẤN ĐỀ}

Trong lĩnh vực y tế hiện nay, kết quả xét nghiệm rất quan trọng cho việc chẩn đoán, điều trị, theo dõi và tiên lượng bệnh, chúng ta cần phải có phương pháp kiểm soát chất lượng khi thực hiện xét nghiệm. Để đảm bảo chất lượng xét nghiệm, mổi đợn vị cần triển khai hệ thống quản lý chất lượng theo hướng dẫn của Thông tư số 01/2013/TT-BYT của Bộ Y tế [8], khuyến cáo của CLSI, CDC và tổ chức y tế thế giới (WHO) [9].

Nội kiểm (IQC) và ngoại kiểm (EQA) có tầm quan trọng hàng đầu trong đảm bảo chất lượng xét nghiệm. Chương trình ngoại kiểm giúp cho các phòng xét nghiệm theo dõi chất lượng một cách có hệ thống, có cái nhìn khách quan về thực trạng của đơn vị mình. EQA giúp phòng xét nghiệm kiểm soát chất lượng xét nghiệm giai đoạn trong xét nghiệm, đồng thời EQA như là một công cư minh chứng cho sự hoàn thiên của hệ thống chất lượng trong phòng xét nghiệm góp phần không nhỏ trong việc chẩn đoán và điều trị cho bệnh nhân [5].

Ở Viêt Nam, tuy đã có thể cung cấp các chương trình $\mathrm{EQA}$ nhưng vẫn chủ yếu là hợp tác với các cơ quan tổ chức uy tín nước ngoài và chưa có bất kỳ một công trình nào trong nước công bố về sản xuất mẫu ngoại kiểm nước tiểu. Do vậy, các mẫu ngoại kiểm nước tiểu khi được phân phối về Việt Nam có giá thành cao, chính vì nguyên nhân nàykhiến cho các khuyến khích tất cả các phòng xét nghiệm tham gia ngoại kiểm gặp nhiêu khó khăn về kinh phí và bị động trong việc cung cấp mẫu ngoại kiểm. Để giải quyết các khó khăn này, chúng ta cần phải chủ động sản xuất và cung cấp các mẫu EQA.

Theo nghiên cứu của Vũ Quang Huy và cộng sự (năm 2018), tỷ lệ các đơn vị tham gia ngoại kiểm tăng qua các năm (24,9\% năm 2015 61,8\% năm 2018). Trong đó phần lớn các đơn vị tham gia chương trình ngoại kiểm sinh hóa, huyết học, 6 tháng đầu năm 2018 tỷ lệ đạt là trên $80 \%$ [4]. Riêng chương trình ngoại kiểm tổng phân tích nước tiểu tính đến năm 2018 vẫn là chương trình nằm trong các chương trình ngoại kiểm phối hợp với RANDOX, số lượng các phòng xét nghiệm tăng liên tục qua hằng năm nhưng tỷ lệ các phòng xét nghiệm tham gia vẫn còn rất thấp.

Chính vì vậy để bảo đảm chất lượng xét nghiệm, đáp ứng được nhu cầu tham gia ngoại kiểm của các phòng xét nghiệm, chúng tôi tiến hành thực hiện đề tài "phường pháp sản xuất mẫu nước tiểu giả định ứng dụng trong chương trình ngoại kiểm tông phân tích nước tiểu". Mục tiêu nghiên cứu. Nghiên cứu phương pháp sản xuất mẫu ngoai kiểm nước tiểu giả định nhằm tiến tới sản xuất ứng dụng trong chương trình ngoại kiểm theo tiêu chuẩn ISO/IEC 17043:2010 [2].

- Đánh giá tính đồng nhất của bộ mẫu đã sản xuất thử nghiệm.

- Đánh giá độ ổn định của bộ mẫu đã sản xuất thử nghiệm.

\section{II. ĐỐI TƯỢNG VÀ PHƯƠ'NG PHÁP NGHIÊN CỨU}

Đối tượng nghiên cứu. Mẫu nước tiểu giả định ứng dụng trong ngoại kiểm tổng phân tích nước tiểu.

Địa điểm nghiên cứu. Trung tâm Kiểm chuẩn chất lượng xét nghiệm y học thuộc Bộ $Y$ tế tại Đại học Y Dược thành phố Hồ Chí Minh, đat tiêu chuẩn ISO 9001:2015 (quốc tễ); ISO 17043 : 2010 (quốc tế).

Thiết kế nghiên cứu. Nghiên cứu thực nghiệm, nghiên cứu sản xuất mẩu nước tiểu giả định ứng dung trong ngoại kiểm tổng phân tích 10 thông số nước tiểu, đánh giá độ đồng nhất và tính ổn định các mẫu đã sản xuất theo thời gian và theo nhiệt độ tại Trung tâm Kiểm chuẩn chất lượng xét nghiệm y học thuộc Bộ Y tế tại Đại học Y Dược thành phố Hồ Chí Minh.

Phương pháp tiến hành. Mẫu nước tiểu âm tính được sản xuất dựa theo công thức điều chế mẫu nước tiểu nhân tạo sử dụng trong đánh giá phòng xét nghiệm [6].

Mẩu nước tiểu có các thông số dương tính sẽ được pha chế dựa trên vật liệu nền là mẫu nước tiểu giả định âm tính đã được pha chế sẵn.

Cách thức pha chế cho từng thông số dương tính [7]:

- Tỷ trong: Mẫu nước tiểu âm tính sau khi tạo ra có tỷ trọng đạt từ 1,015-1,025. Điều chỉnh tỷ trọng cao hay thấp bằng cách thêm vào một lượng chất hòa $\tan \mathrm{NaCl}$ và $\mathrm{KCl}$ hay giảm đi trong giai đoạn tao mẫu nước tiểu âm tính.

- pH: Mẫu nước tiểu âm tính sau khi tạo ra có 
nồng độ $\mathrm{pH}$ từ 5,0-6,0. Muốn giảm pH nước tiểu ta cho thêm vào một lượng $\mathrm{HCl} 1 \mathrm{~N}$ xác định cho đến khi đạt được độ pH mong muốn, để tăng $\mathrm{pH}$ nước tiểu ta thềm vào một lượng $\mathrm{NaOH}$ cho đến khi đạt được độ pH cần điều chỉnh.

- Glucose: Để tạo mẫu nước tiểu dương tính với glucose, sử dụng bột glucose $100 \%$.

- Nitrite: Sử dụng tinh thể sodium nitrite để tạo mẫu nước tiểu dương tính với nitrite.

- Protein: Tạo protein trong nước tiểu bằng cách thêm vào một lượng huyết thanh đã biết trước nồng độ protein cho đến khi đạt được nồng độ mong muốn.

- Hồng cầu: Sử dưng mẫu hồng cầu rửa đã biết trước nồng độ để tạo mẫu nước tiểu dương tính đối với hồng cầu.

- Keton: Sử dụng acetoacetic acid 99,5\% để tạo mẫu nước tiểu dương tính với keton.
- Bạch câu: Emzym esterase của bạch cầu là chất được sử dụng để phát hiện sự có mặt của bạch cầu trong nước tiểu.

- Bilirubin: Bột bilirubin được thêm vào để tạo kết quả dương tính với bilirubin trong nước tiểu giả định.

- Urobilinogen: dung dịch urobilinogen đã biết trước nồng độ được thêm vào mẫu nước tiểu giả định.

Mẫu sau khi được sản xuất sẽ được đánh giá tiền phân tích, độ đồng nhất và độ ổn định theo thời gian và theo nhiệt độ theo hướng dẫn của Tiêu chuẩn ISO GUIDÉ 35:2017 về Mẫu chuẩn Nguyên tắc chung và nguyên tắc thống kê trong chứng nhận với một số loại mẫu chuẩn [1] và Tiêu Chuẩn Quốc Gia TCVNN 9596:2013 tương ứng với ISO 13528:2015 về Phương pháp thống kê dùng trong thử nghiệm thành thạo bằng so sánh liên phòng thí nghiệm [3].

\section{KẾT QUẢ NGHIÊN CỨU}

Xây dựng hoàn tất quy trình sản xuất mẫu nước tiểu giả định ứng dụng trong ngoại kiểm

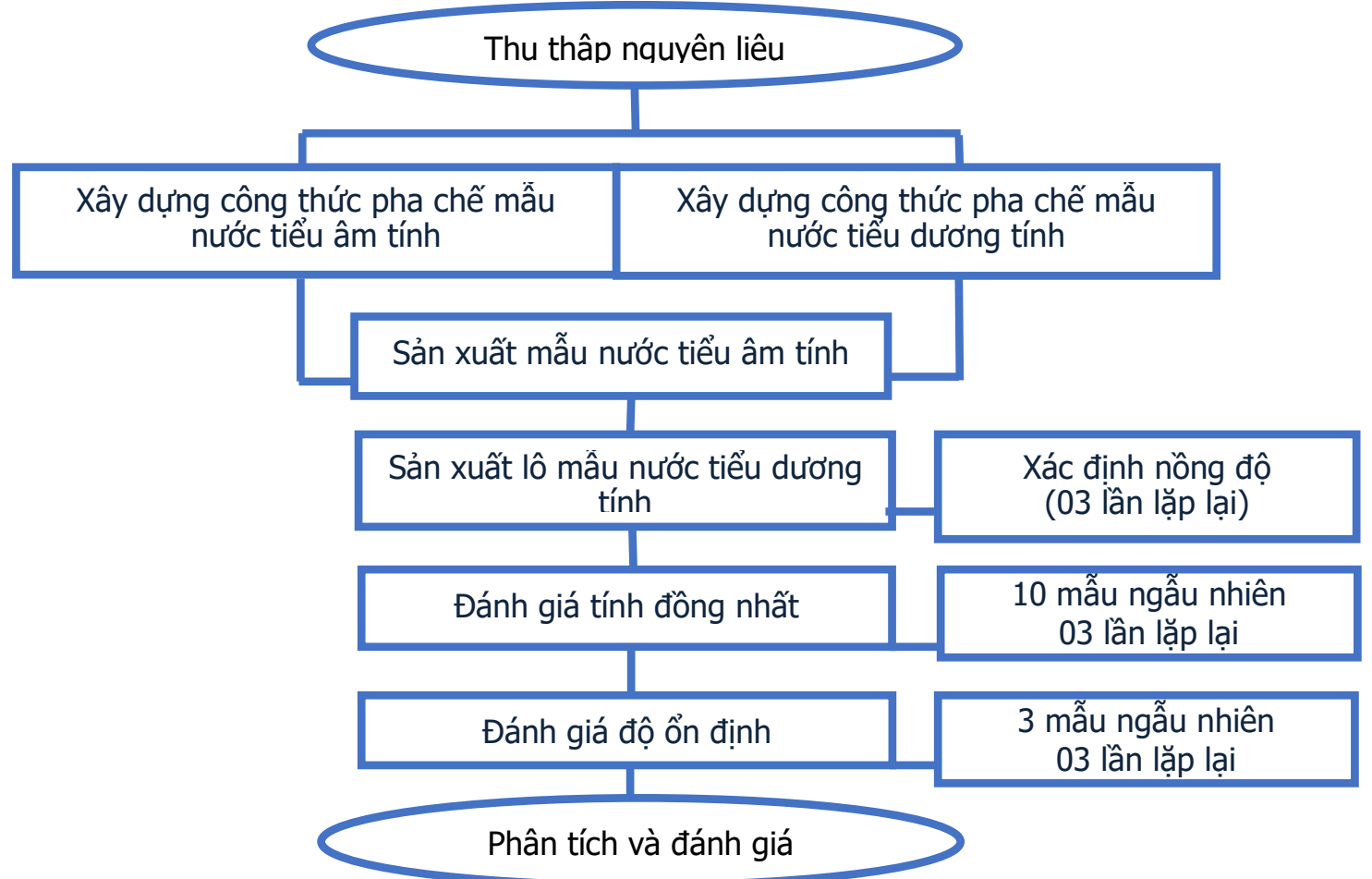

Hình 1. Sơ đồ quy trình thực hiện nghiên cứu sản xuất mẫu nước tiểu giả định

Sản xuất thử nghiệm mẫu nước tiểu giả định 10 thông số được pha chế dựa trên chất nền là mẫu nước tiểu âm tính.

Bộ mẫu nước tiểu âm tính được sản xuất có các tính chất về màu sắc, độ đục trong và thành phần hóa học tương đồng với mẫu nước tiểu thật. Bộ mấu nước tiểu dương tính với từng thổng số nhất định được sản xuất bằng cách thêm các chất tương ứng vào vật liệu nền là mẫu nước tiểu âm tính giả định và được điều chỉnh nồng độ để cho ra kết quả như dự định (SG = $1,010, \mathrm{pH}=8,0, \mathrm{GLU}=500 \mathrm{mg} / \mathrm{dL}, \mathrm{KET}=$ $100 \mathrm{mg} / \mathrm{dL}$, NIT $=$ positive, $\mathrm{LEU}=$ 25leukocyte/ $\mu \mathrm{L}, \mathrm{URO}=2 \mathrm{mg} / \mathrm{dL}, \mathrm{BIL}=17 \mu \mathrm{mol} / \mathrm{L}$, $\mathrm{BLO}=50$ erythrocytes $/ \mu \mathrm{L}, \mathrm{PRO}=100 \mathrm{mg} / \mathrm{dL}$ ). 
Bảng 1. Kết quả bộ mẫu dương tính 10 thông số được sản xuất

\begin{tabular}{|c|c|c|c|c|c|c|c|c|c|c|}
\hline Thông số & SG & pH & GLU & KET & NIT & LEU & URO & BIL & BLO & PRO \\
\hline Kết quả & 1,010 & 8,0 & $\begin{array}{c}500 \\
\mathrm{mg} / \mathrm{dL}\end{array}$ & $\begin{array}{c}100 \\
\mathrm{mg} / \mathrm{dL}\end{array}$ & + & $\begin{array}{c}25 \\
\text { leuko/ } \mu \mathrm{L}\end{array}$ & $\begin{array}{c}2 \\
\mathrm{mg} / \mathrm{dL}\end{array}$ & $\begin{array}{c}17 \\
\mu \mathrm{mol} / \mathrm{L}\end{array}$ & $\begin{array}{c}50 \\
\mathrm{ery} / \mathrm{\mu L}\end{array}$ & $\begin{array}{c}100 \\
\mathrm{mg} / \mathrm{dL}\end{array}$ \\
\hline
\end{tabular}

Mẫu sau khi sản xuất được đánh giá tiền phân tích, đánh giá độ đồng nhất sau đó được phân thành 2 lô mẫu để đánh giá độ ổn định dài hạn theo thời gian ( 3 tháng) và theo nhiệt độ bảo quản $\left(2-8^{\circ} \mathrm{C}\right.$ và $\left.-20^{\circ} \mathrm{C}\right)$.

Bảng 2. Kêt quả tiền phân tích

\begin{tabular}{|c|c|c|c|c|c|c|c|c|c|c|}
\hline Thông số & SG & pH & GLU & KET & NIT & LEU & URO & BIL & BLO & PRO \\
\hline $\begin{array}{c}\text { Kết quả } \\
\text { (p- value }\end{array}$ & 0,8865 & 0,9135 & 0,9853 & 0,9997 & + & 0,9830 & 0,9853 & 0,9968 & 0,9853 & 0,9853 \\
\hline
\end{tabular}

Bộ mẫu trước khi chia lô được chọn 10 mấu để đo nhằm đánh giá kết quả ban đầu của bộ mẫu sau khi sản xuất trước khi chia nhỏ thành các mẫu.

Bảng 3. Kết quả đánh giá độ đồng nhất

\begin{tabular}{|c|c|c|c|c|c|c|c|c|c|c|}
\hline Thông số & SG & pH & GLU & KET & NIT & LEU & URO & BIL & BLO & PRO \\
\hline Kết quả (p - value) & 0,8091 & 0,9135 & 0,9853 & 0,9997 & + & 0,9853 & 0,9853 & 0,9909 & 0,9968 & 0,9979 \\
\hline
\end{tabular}

Giá trị p-value của cả 10 thông số đều lớn lơn 0,05 nên sự khác biệt không có ý nghĩa thông kê về kết quả của cả 10 thông số trong 10 mẫu được chọn để đánh giá độ đồng nhất. Bộ mẫu sản xuất đạt tính đồng nhất và được chia thành 2 lô bảo quản ở 2 điều kiện nhiệt độ khác nhau $\left(2-8^{\circ} \mathrm{C}\right.$ và $\left.-20^{\circ} \mathrm{C}\right)$.

Bảng 4. Kết quả đánh giá độ ổn định dài hạn ở điều kiện nhiệt độ 2-8 $\mathrm{C}(p$-value)

\begin{tabular}{|c|c|c|c|c|c|c|c|c|c|c|}
\hline & SG & pH & GLU & KET & NIT & LEU & URO & BIL & BLO & PRO \\
\hline 1 tuần & 0,1541 & 0,9454 & 0,8863 & 0,0656 & + & 0,8629 & 0,8629 & 0,9242 & 0,3376 & 0,6535 \\
\hline 2 tuần & 0,4382 & 0,5520 & 0,5475 & 0,3598 & + & 0,5223 & 0,5223 & 0,0930 & 0,7004 & 0,8512 \\
\hline 2- 4 tuần & 0,5490 & 0,5520 & 0,4111 & 0,3598 & + & 0,1759 & 0,8629 & 0,0930 & 0,7915 & 0,2612 \\
\hline $3^{\circ} \mathrm{C} 6$ tuần & 0,4382 & 0,9454 & 0,8863 & 0,0656 & + & 0,5223 & 0,5223 & 30 & 76 & 535 \\
\hline 8 tuân & 0,4382 & 0,5520 & 0,4111 & 0,3598 & + & 0,0454 & 0,1759 & 97 & 0,7004 & 0,8512 \\
\hline 12 tua & 0,5490 & 0,2231 & 0,8863 & 0,0656 & + & 0,0015 & 0,0454 & 0,0034 & 0,1115 & 0,4261 \\
\hline
\end{tabular}

Lô mấu bảo quản ở điều kiện nhiệt độ $2-8^{\circ} \mathrm{C}$ có các thông số SG, pH, GLU, KET, BLO, PRO đạt độ ổn định trong thời gian 3 tháng với giá trị $p>0,05$. Thông số NIT đạt độ ổn định 3 tháng với giá trị dương tính như ban đầu. Thông số LEU chỉ đạt độ ổn định trong 6 tuần, giá trị $\mathrm{p}$ ở tuần 8 là $\mathrm{p}=$ $0,0454<0.05$. Thông số BIL đạt độ ổn định trong 6 tuần, giá trị $p$ ở tuần 8 là $p=0,0197<0,05$. Thông số URO đạt độ ổn định trong 8 tuần, giá trị p ở tuần 12 là $0,0454<0,05$.

Bảng 5. Kết quả đánh giá độ ổn định dài hạn ở điều kiện nhiệt độ $-20^{\circ} \mathrm{C}$ ( $p$-value)

\begin{tabular}{|c|c|c|c|c|c|c|c|c|c|c|c|}
\hline & & SG & pH & GLU & KET & NIT & LEU & URO & BIL & BLO & PRO \\
\hline \multirow{5}{*}{$20^{\circ} \mathrm{C}$} & 1 tuần & 0,4382 & 0,9454 & 0,8863 & 0,3598 & + & 0,8629 & 0,8629 & 0,9242 & 0,3376 & 0,2612 \\
\cline { 2 - 11 } & 2 tuâan & 0,4379 & 0,4318 & 0,5475 & 0,0656 & + & 0,5223 & 0,5223 & 0,3424 & 0,7915 & 0,6535 \\
\cline { 2 - 10 } & 6 tuần & 0,9576 & 0,5520 & 0,4111 & 0,5839 & + & 0,1759 & 0,8629 & 0,3424 & 0,7004 & 0,2612 \\
\cline { 2 - 10 } & 0,1541 & 0,9454 & 0,5475 & 0,3598 & + & 0,5223 & 0,5223 & 0,0930 & 0,7915 & 0,6535 \\
\cline { 2 - 9 } & 8 tuần & 0,9576 & 0,9454 & 0,4111 & 0,3598 & + & 0,5223 & 0,5223 & 0,3424 & 0,7004 & 0,8512 \\
\hline & 12 tuần & 0,5490 & 0,5520 & 0,8863 & 0,0656 & + & 0,1759 & 0,1759 & 0,0930 & 0,7004 & 0,8512 \\
\hline
\end{tabular}

Lô mầu bảo quản ở điều kiện nhiệt độ- $20^{\circ} \mathrm{C}$, tất cả 10 thông số $\mathrm{SG}, \mathrm{pH}, \mathrm{GLU}, \mathrm{KET}$, LEU, URO, $\mathrm{BIL}, \mathrm{BLO}, \mathrm{PRO}$ đều đạt độ ổn định trong thời gian 3 tháng với giá trị $\mathrm{p}>0.05$. Lô mẫu bảo quản ở điều kiện nhiệt độ $2-8^{\circ} \mathrm{C}$ có các thông số SG, pH, GLU, KET, BLO, PRO đạt độ ổn định trong thời gian 3 tháng với giá trị $\mathrm{p}>0,05$.

Bảng 6. Kết quả phân tích độ ổn định ngắn hạn

\begin{tabular}{|c|c|c|c|c|c|c|c|c|c|c|}
\hline Thời gian & SG & pH & GLU & KET & NIT & LEU & URO & BIL & BLO & PRO \\
\hline 5 ngày & 0,7990 & 0,7645 & 0,7990 & 0,2207 & + & 0,7645 & 0,7990 & 0,7645 & 0,6541 & 0,7990 \\
\hline 8 ngày & 0,2308 & 0,3085 & 0,2308 & 0,2207 & + & 0,7645 & 0,6541 & 0,4142 & 0,6541 & 0,7990 \\
\hline 10 ngày & 0,6451 & 0,7645 & 0,7990 & 0,2207 & + & $\mathbf{0 , 0 3 0 8}$ & $\mathbf{0 , 0 2 4 7}$ & $\mathbf{0 , 0 3 0 8}$ & 0,7990 & 0,7990 \\
\hline
\end{tabular}

Khi so sánh với nồng độ tại thời điểm ban đầu sau sản xuất, mấu nước tiểu giả định dùng trong ngoại kiểm tổng phân tích nước tiểu có các thông số leukocytes, bilirubin và urobilinogen đạt độ ổn định trong thời gian 8 ngày vận chuyển ( $p$-value $<0,05$ ), các thông số còn lại đạt độ ổn định trong thời gian 8 ngày vận chuyển ( $\mathrm{p}-$ value $>0,05)$. 


\section{BÀN LUÂN}

Sản xuất thử nghiệm mẫu nước tiểu giả định bao gồm mâuu nước tiểu âm tính và mẫu dương tính được pha chế dựa trên chất nền là mẫu nước tiểu âm tính. Quy trình sản xuất mẫu nước tiểu giả định bắt đâu từ khi chuẩn bị nguyên liệu sản xuất. Mẫu nước tiểu giả định được sản xuất dựa trên công thức sản xuất mẫu nước tiểu dùng trong phòng thí nghiệm và đáp ứng được mục tiêu của việc ngoại kiểm nhằm kiểm tra chất lượng về trang thiết bị, hóa chất và kỹ thuật của người thực hiện xét nghiệm tổng phân tích nước tiểu.

Các nguyên liệu sử dụng trong quá trình sản xuất được đảm bảo nguồn gốc và tính an toàn tuyệt đối cho người thực hiện. Các hóa chất sử dụng có nguồn gốc rõ ràng và đạt những tiêu chuẩn nhất định. Những loại chế phẩm máu được sàng lọc kỹ trước khi thực hiện sản xuất, mẫu máu được mua tại Bệnh viện Huyết học Truyền máu thành phố Hồ Chí Minh.

Các giai đoạn tiếp theo được thực hiện theo ISO 17043:2010 về việc đánh giá sự phù hợp Yêu cầu chung đối với thử nghiệm thành thạo. Và chúng tôi đánh giá độ đồng nhất và độ ổn định của mẫu sản xuất theo ISO 13528:2015 và theo hướng dẫn của ISO Guide 35:2017 về Mẫu chuẩn - Nguyên tắc chung và nguyên tắc thống kê trong chứng nhận.

Độ đông nhất và độ ổn định của của bộ mẫu sản xuất theo thời gian và điêu kiện nhiệt độ. Bộ mẫu sau khi sản xuất được chia thành 2 lô bảo quản 2 điêu kiện nhiệt độ là $2-8^{\circ} \mathrm{C}$ và $-20^{\circ} \mathrm{C}$ trong 3 tháng nhằm đánh giá sự ổn định của các thông số theo 2 điều kiện nhiệt độ khác nhau và theo thời gian. Từ kết quả của đánh giá sự ổn định ta thây: Lô mẫu bảo quản ở điều kiện nhiệt độ $-20^{\circ} \mathrm{C}$ đạt độ ổn định trong 3 tháng ở tất cả 10 thống số. Lô mẫu bảo quản ở nhiệt độ 2 $8^{\circ} \mathrm{C}$ các thông số LEU, URO, BIL có độ ổn định ngắn hơn 3 tháng (LEU và BIL ổn định 6 tuần, URO ổn định 12 tuần). Điều này có thể do khi bảo quản ở $2-8^{\circ} \mathrm{C}$ thì enzyme esterase leukocyte bị giảm hoạt tính theo thời gian vì nhiệt độ bảo quản của enzyme là nhiệt độ $-20^{\circ} \mathrm{C}$, riêng URO và $\mathrm{BIL}$ có thể bị ảnh hưởng bởi yếu tố ánh sáng.

Đối với độ ổn định ngắn hạn, cả 10 thông số của 6 mẫu gửi đi đến ngày thứ 8 đều đạt giá trị $\mathrm{p}$ - value $>0.05$ chứng tỏ mẫu ổn định trong thời gian 8 ngày ở điều kiện vận chuyển. Riêng 3 thông số bilirubin, urobilinogen, leukocytes đến ngày thứ 10 không còn ổn định $(p-$ value < $0,05)$, các thông số còn lại điều ổn định. Ta thấy 3 thông số này dễ bị thay đổi bởi nhiệt độ và ánh sáng nên không bền vững lâu trong điều kiện vận chuyển.

\section{KẾT LUẬN}

Bộ mẫu nước tiểu giả định dương tính với từng thông số cụ thể: tỷ trọng, pH, glucose, protein, urobilinogen, bilirubin, nitrite, leukocyte, keton, blood được sản xuất thử nghiệm thành công nhằm ứng dụng vào chương trình ngoại kiểm tổng phân tích 10 thông số nước tiểu.

Các bộ mẫu sau khi sản xuất đều đồng nhất với nhau. Mẫu nước tiểu sản xuất ra đạt độ ổn định trong thời hạn 3 tháng ở điều kiện nhiệt độ $-20^{\circ} \mathrm{C}$. Riêng bộ mẫu giữ ở $2-8^{\circ} \mathrm{C}$, leukocyte và bilirubin ổn định chỉ trong 6 tuân, urobilinogen ổn định trong 8 tuần, những thông số còn lại ổn định trong 3 tháng.

LỜI CẢM ON. Chúng tôi gữi lời cảm ơn Đại học $Y$ dược đã tài trợ để thực hiện nghiên cứu này.

\section{TÀI LIỆU THAM KHẢO}

1. Tiêu Chuẩn ISO Guide $35: 2017$, Mẫu chuẩnNguyên tắc chung và nguyên tắc thống kê trong chứng nhận, tr.18-43.

2. Tiêu Chuẩn Quốc Gia TCVN 17043:2011 ISO 17043:2010 (2011), Đánh giá sự phù hợp - yêu cầu chung đối với thử nghiệm thành thạo, tr.13-23.

3. Tiêu Chuẩn Quốc Gia TCVN 9596:2013 ISO 13528:2003 (2013), Phương pháp thống kê dùng trong thử nghiệm thành thạo bằng so sánh liên phòng thí nghiêm, 56-61.

4. Vũ Quang Huy và các cộng sự (2018), "Nâng cao chất lượng xét nghiệm y học từ 2015 đến 6 tháng đầu 2018 qua các chương trình ngoại kiểm Trung tâm Kiểm chuẩn chất lượng xét nghiệm y học Bộ Y tế tại Đại học Y Dược thành phố Hồ Chí Minh", Y học Ṫp. Hồ Chí Minh. 22(5), tr. 290 - 297.

5. Clinical and laboratory standards institute QMS01-A4 (2011), "Quality Management System: A model for Laboratory Services; Approved Guideline-Fourth Edition".

6. Brian Shmaefsky (1995), "Artificial Urine for Laboratory Testing", The American Biology Teacher. 57(7), tr. 428-430

7. Susan King Strasinger và Marjorie Schaub Di Lorenzo (2014), Urinalysis and body fluids, FA Davis.

8. Bộ Y Tế (2013), Thông tư 01 Hướng Dẫn Thực Hiện Quản Lý Chất Lượng Xét Nghiệm Tại Cơ Sở Khám Chữa Bệnh.

9. WHO, "Overview of External Quality Assessment (EQA)", tr. 1-8. 